\title{
A clinical guide to endodontics - update part 1
}

\author{
P. V. Carrotte
}

IN BRIEF

- Considers the changes that have occurred in the thinking and practice of root canal treatment since $A$ clinical guide to endodontics was published.

- Provides greater guidance on the use of NiTi endodontic instruments, now considered by many to be essential for effective canal preparation.

- Discusses developments in irrigation and obturation, both essential for the best possible prognosis of treatment.

This is the first of two opinion papers that aim to provide a review of changes and developments that have occurred within the field of root canal treatment for both permanent and primary teeth since the publication in 2004 of the BDJ's textbook A clinical guide to endodontics. This, the first part, considers the changes in thinking and practice that have occurred with regard to the treatment of permanent teeth, in particular the continued significant move toward the use of nickel titanium rotary instruments. Knowledge of the changes discussed in this paper is essential both for the best possible prognosis of treatment, and when obtaining informed or valid consent to treatment.

\section{INTRODUCTION}

The British Dental Journal's $(B D J)$ series and subsequent textbook $A$ clinical guide to endodontics was written and subjected to editorial review during 2002-3, being published as a book in November 2004. The book replaced the $B D J$ 's previous endodontic textbook, Stock and Nehammer's Endodontics in practice, published in 1990, and considered the changes in endodontic concepts and clinical practice in the intervening thirteen years. The Editor-in-Chief of the BDJ, Dr Stephen Hancocks, has suggested that it might now be appropriate to review what further developments have taken place in endodontic practice over the last five years. It is, of course, essential that today's practitioner keeps up to date with current teaching and practice. Some changes may be minor while some may have a significant impact on practice. For example, the philosophy

\footnotetext{
Senior Clinical University Teacher and Associate Specialist in Endodontics, Unit of Adult Dental Care, Glasgow Dental Hospital and School, 378 Sauchiehall Street, Glasgow, G2 3JZ

Correspondence to: Mr Peter Carrotte

Email: peter.carrotte@gmail.com
}

\section{Refereed Paper}

Accepted 16 June 2008

DOI: $10.1038 /$ sj.bdj.2009.6

${ }^{\circledR}$ British Dental Journal 2009; 206: 79-84 of the prescription of prophylactic antibiotic therapy for patients with a history of rheumatic heart fever has changed completely since the textbook was published. National Institute for Health and Clinical Excellence (NICE) guidelines ${ }^{1}$ now suggest that such cover is not indicated and the long-established practice should be discontinued as research has clearly shown the theoretical benefits (if there ever were any) are significantly less than the potential risks.

At the outset it must be stressed that root canal treatment is not just a technical exercise performed by 'root canal technicians'. It is essential that the skilled practitioner is fully conversant with root canal morphology; is able to diagnose and plan treatment for all endodontic lesions; and understands and practises effective isolation and aseptic techniques. Each year audit reveals an increase in the number of root canal treatments carried out in the UK, both de novo and re-treatment cases. In the latter, success will be limited unless the reason for failure has been correctly diagnosed and treatment planned accordingly. The relevant chapters on these aspects in the original text are largely unchanged today. Root canal morphology does not change rapidly! Perhaps the only pertinent observation would be with regard to the second mesio-buccal canal in an upper first permanent molar. Buhrley et $a l .^{2}$ recently reported that the incidence of finding this canal in three distinct groups of practitioners was 17\%, 63\% and $71 \%$. The first group used no magnification, the second group wore dental loupes, and the third used an operating microscope. An unidentified, and therefore uncleaned, canal can be a major cause of failure.

The significant difference when using dental loupes compared with much less further improvement with an operating microscope is interesting. Dental loupes may be purchased today for anything between $£ 100$ and £2,000 and are therefore an option for all practitioners, indeed many dental students are now purchasing these at the start of their undergraduate careers. The top of the range models include a light source, bringing the benefits of these loupes very close to the more expensive alternative. Operating microscopes vary from $£ 5,000$ to $£ 30,000$ and may well be more appropriate to specialist practitioners. Sadly, once these have been used it is very difficult to go back! The astounding improvement in vision is due in part to the greater magnification, but is particularly due to the integral operating light. One is able to see clearly the floor of the pulp 
chamber, canal orifices, tertiary dentine deposits, etc, and this leads to greatly reduced operator stress. Coupled with the resultant improved operator posture and comfort, the purchase of these adjuncts to treatment is highly recommended and will result in better root canal treatment to a significantly higher standard.

The reader who seeks guidance on the quality standards for endodontic treatment expected of the competent practitioner should refer to the recently updated consensus report of the European Society of Endodontology. ${ }^{3}$ This is a very useful document when revising for both undergraduate and postgraduate examinations.

There are, however, four areas where significant change in concept or practice has occurred. Firstly, there has been a significant move away from the step-back technique of canal preparation using iso 2\% taper hand files. Most UK and European dental schools are now teaching the use of greater taper hand or rotary nickel titanium files in a crown-down technique. Secondly, these preparation techniques may require a different method of canal obturation. The long-accepted 'gold-standard norm' of cold lateral compaction of master and accessory gutta percha points with a root canal sealer may not be appropriate for these greater taper techniques. Thirdly, there has been a significant move in the practice of endodontic surgery to the routine use of the operating microscope and mineral trioxide aggregate (MTA). Finally, the traditional materials and methods used in endodontic therapies for primary teeth have come under scrutiny. The first three of these will be considered here, and a second paper will be devoted to the subject of pulpal therapy in primary teeth. It should be remembered, however, that the main purpose of the BDJ's Clinical Guide series is to provide practical information to guide and instruct the general dental practitioner and undergraduate student. Practitioners intending to perform endodontic surgery to today's accepted standards should refer to the relevant specialist surgical texts and undergo appropriate further training in these techniques.

\section{PREPARING THE ROOT CANAL SYSTEM}

\section{Irrigation}

Success in root canal treatment is dependent upon the removal of all infective agents and necrotic material from the entire root canal system. The purpose of root canal instruments is to create sufficient space for the ingress of effective irrigant solutions. Unless appropriate antibacterial solutions are able to penetrate to the apical constriction and remain in contact with the canal walls and dentine tubules for a sufficient length of time, micro-organisms may remain in the canal. However effective the obturation might be, late failure is the probable consequence. Although many papers have been published on this subject over the years, the recent paper by Hsieh et al. ${ }^{4}$ merits consideration. The researchers used thermal imaging to measure the penetration and flow of irrigant throughout the root canal. They compared the depth of penetration of three sizes of irrigating needle, (23 gauge, 25 gauge and 27 gauge) with root canals prepared to different apical sizes using a standard step-back preparation. They reported that unless the tip of the needle was able to penetrate to $3 \mathrm{~mm}$ from the apical constriction, effective irrigation was not achieved. Furthermore, to enable the finest 27 gauge needle to penetrate to this depth the canal must be prepared to at least size 30 , for a 25 gauge needle to at least size 45 and for a 23 gauge at least size 50. Additionally, if the tip of the needle was held at 6 $\mathrm{mm}$ from the apex, irrigant only flowed throughout the canal when the finest 27 gauge needle was used and the apical preparation was size 50. Unfortunately the canals in this research were only prepared using standard iso $2 \%$ taper hand files with the step-back technique. It must be asked whether canals prepared with modern greater taper file systems, as discussed later, would have shown different results.

Sodium hypochlorite remains the irrigant of choice for routine cases. It is generally accepted that a second irrigant should be used to remove the smear layer, either EDTA or citric acid. It seems logical that removing the smear layer will expose micro-organisms in dentine tubules and facilitate greater contact with biofilms, but research evidence of the benefits of smear layer removal is limited. Practitioners should always be aware that some micro-organisms are more resistant to the effect of sodium hypochlorite than others, for example Radcliffe et al..$^{5}$ found Enterococcus faecalis to be resistant. Bonsor et al. ${ }^{6}$ have published work on the use of photoactive disinfection showing improved canal disinfection and there is ongoing research into this technique. It should be remembered when selecting an appropriate irrigant that as well as antibacterial action, irrigants should possess additional properties such as good detergent action, low surface tension, good tissue dissolution and no noxious residues.

It must, of course, be stressed that irrigation must be passive. The tip of the needle should be advanced to within 3 $\mathrm{mm}$ of the apical constriction and then withdrawn slightly. It is good practice to place a rubber stop or marker on the needle to measure the exact depth of penetration. Light finger pressure only should be applied. If irrigant is expressed into the periradicular tissues under pressure, a severe inflammatory reaction may arise instantly, as detailed recently in this Journal by Witton and Brennan. Should this occur, the patient should be reassured that the swelling will resolve in two to three days. Anti-inflammatory agents should be prescribed, together with antibiotics as infected material may have been expressed from the root canal (Fig. 1).

\section{Instrumentation}

Nickel titanium (NiTi) alloy has particular characteristics of super-elasticity and shape memory. This has facilitated considerable improvement in canal shaping procedures, particularly in curved canals, and it would appear that these have been adopted by the majority of practitioners. Many reports have appeared in the dental literature suggesting that these techniques are leading to an improvement in the quality of root canal treatments. Most of these have been based on canal preparations in the teaching laboratory, but Molander et al. ${ }^{8}$ report improvement in clinical performance as well. 


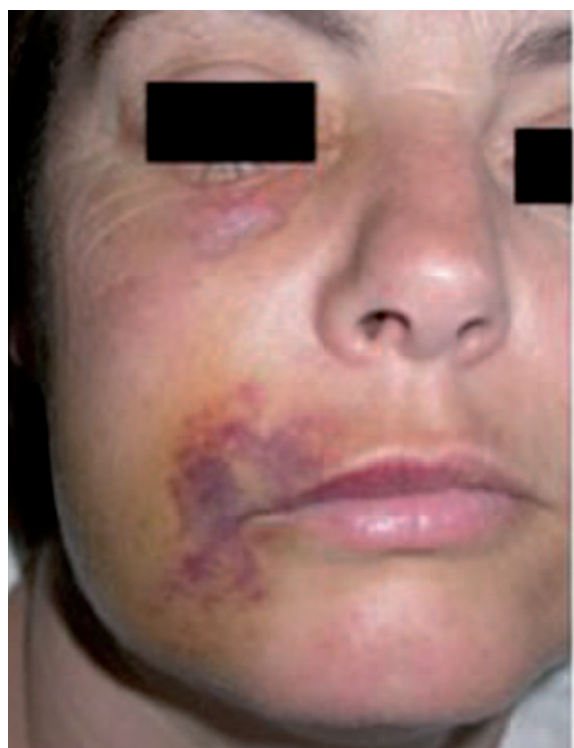

Fig. 1 Initial presentation of a patient following a sodium hypochlorite incident with swelling and ecchymosis. (Photograph published with kind permission of R. Witton and P. Brennan ${ }^{7}$ )

Most manufacturers and distributors of endodontic instruments have developed their own NiTi instruments with various cross-sections, pitches and tapers. When selecting a particular instrument the individual practitioner should consider the supplier's specific documentation and the supporting research evidence, both in vitro and in vivo. What follows is a general consideration of NiTi instrumentation and is not a recommendation or criticism of any particular instrument or technique.

Unfortunately, in spite of the aforementioned benefits of NiTi instrumentation, reports are also appearing showing a relatively high incidence of instrument fracture, which will block narrow, curved canals and hinder or prevent adequate shaping and cleaning procedures. It must be clearly understood from the outset that rotary NiTi instruments are intended to widen the canal space once an initial guide-path (sometimes referred to as a flight-path) has been created with conventional hand files. NiTi rotary instruments are not designed or intended for exploration and negotiation of a previously uninstrumented canal. It is essential that this protocol is followed.

Straight line access is essential. Once the canal orifices have been identified in an adequate access cavity and explored by watch-winding a fine hand file to the

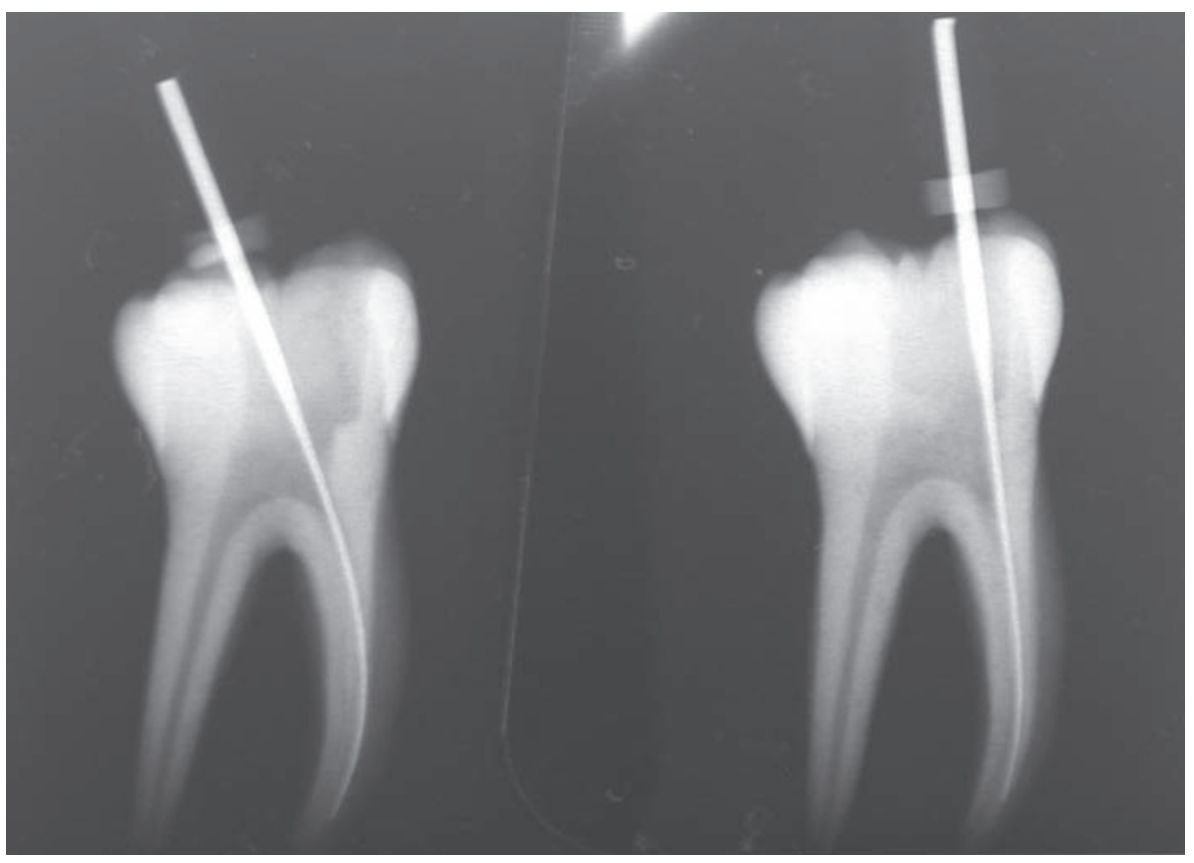

Fig. 2 Radiographs taken in the preclinical laboratory showing how selective removal of dentine facilitates straight line access

estimated working length taken from the pre-operative radiograph, an orifice shaper (or gates glidden drill) should be used to improve the straight line access as shown in Figure 2. Dentine is removed by brushing away from the canal orifice in a direction dictated by the name of the canal. Thus dentine is removed in a mesio-buccal direction from the orifice of the mesio-buccal canal in a lower molar, removed palatally from the orifice of the palatal canal in an upper molar, and so on.

Once good straight line access has been achieved, standard iso hand files are used with a watch-winding or balanced force technique to widen the canal to the estimated working length. Some manufacturers' guidelines recommend that the canal should be widened to a size \#15 but the author prefers size \#20. An EDTA paste eases the procedure by chelating the dentine and lubricating the instrument.

NiTi instruments will usually separate for one of two reasons, cyclic fatigue or torsional stress. Cyclic fatigue may be reduced by setting the correct slow speed on the endodontic motor and by using the file for as brief a period as possible. Once the shape has been created it should be withdrawn. Nothing is gained by repeatedly entering the canal unless a deliberate 'brushing' action is being used to shape the walls of an oval canal.

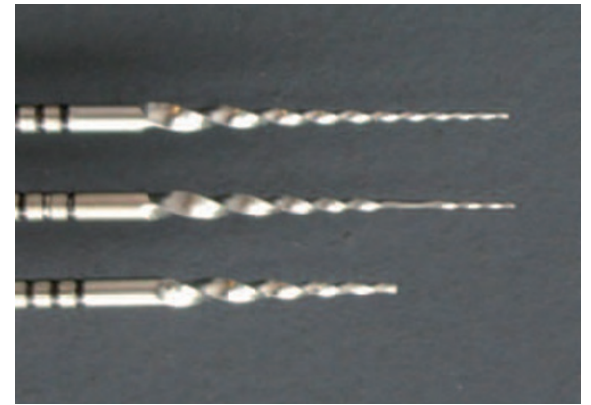

Fig. 3 Three NiTi files showing a brand new file at the top, a file showing evidence of torsional flute damage in the middle, and at the bottom one that has separated

Torsional stress, however, is probably the more important. If the tip of a file is forced into a narrow canal, the instrument will exceed its torsional limit, particularly if a high torque setting has been set on the motor, and the tip will separate. Figure 3 shows an instrument removed from a canal during a laboratory training session with its tip missing, and another instrument removed just before separation occurred. Instead of forcing the instrument down the canal, more space should be created coronally to enable the whole length of the instrument to widen the canal. Preparation should be seen as a series of waves moving down the canal. A large instrument prepares space coronally. The next instrument in the sequence moves a little further down, perhaps only a few millimetres. Once the sequence of sizes has been used, a 


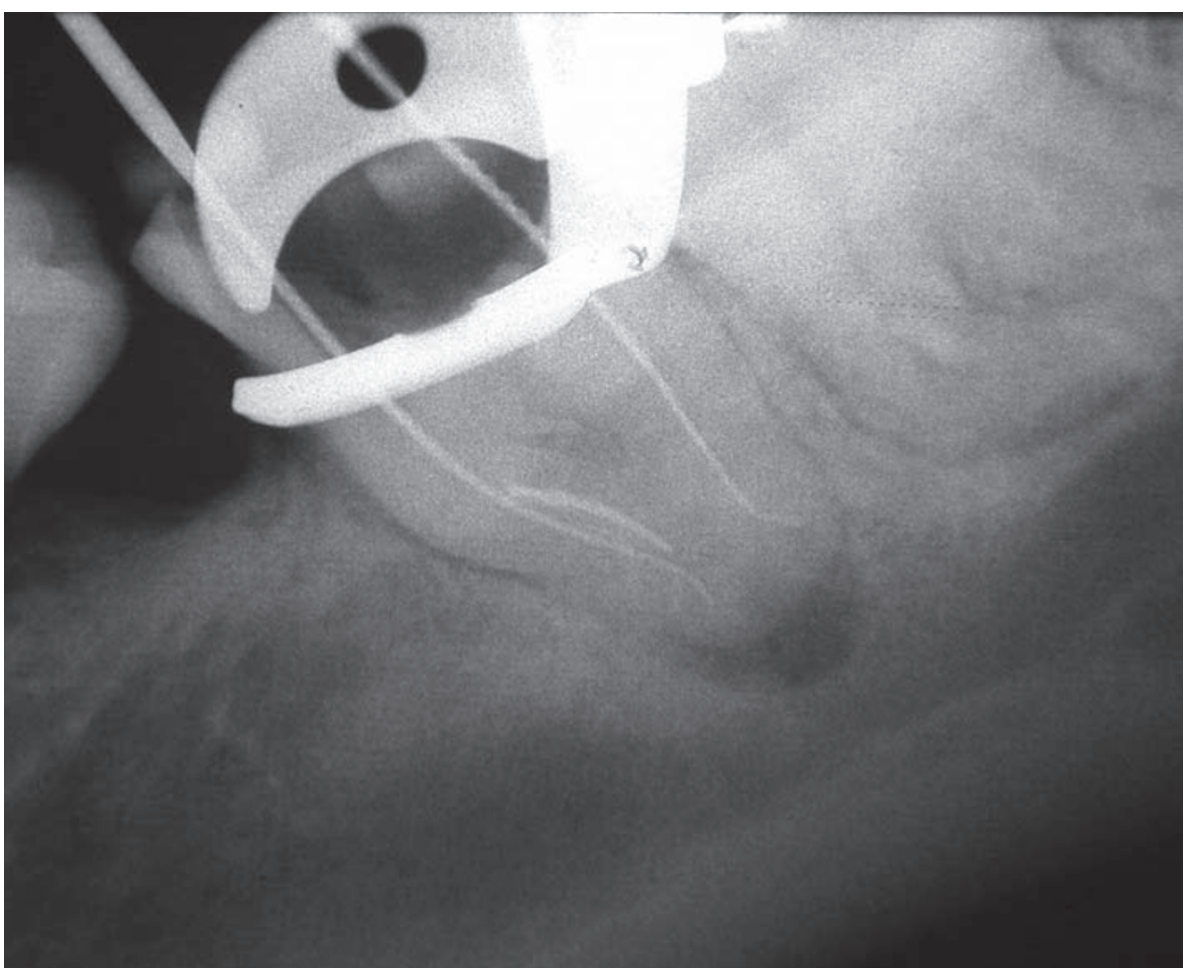

Fig. 4 A radiograph showing how a NiTi file may separate if used to negotiate a root canal with a double curve

second wave commences, creating more space coronally and allowing deeper penetration. The temptation to force an instrument to widen and deepen a narrow canal should always be resisted. If a narrow canal is proving difficult to negotiate to full working length then hand files should be used to prepare the apex with far greater control.

Once the working length has been confirmed and the rotary instrument has been used to the apex, iso hand files should be used to feel or gauge the size of the apex and enlarge it accordingly. Irrigation will then be effective to the apex and the case prognosis will be improved. The file is inserted to length and its fit checked simply by feel. If the tip is loose at working length the apical preparation should be enlarged. If the file is tight, even exhibiting slight 'tug-back' on withdrawal, the preparation is complete.

\section{Working length}

There has been a great improvement in the accuracy of apex locators in recent years and some practitioners no longer expose a working length radiograph. Provided a good pre-operative radiograph is available to calculate the estimated working length, and provided the electronic measurement accords with this, the radiograph is indeed not required. It has been suggested by some authorities that for medico-legal reasons a radiograph should always be taken with either an endodontic instrument or a master gutta percha point. This advice misunderstands the difference between these two methods of working length confirmation. As stated before, provided that the electronic measurement concurs with that calculated from the pre-operative film then the electronic measurement will be more accurate than any radiographic estimation. A radiograph would only be required if the electronic measurement did not concur with the estimated length. This may occur if there is a large coronal restoration or crown which is contacting the file, if there is salivary contamination of the access cavity, or in retreatment cases. In these and other situations where the accuracy of the electronic measurement appears unreliable, a radiograph must be exposed and the subjective estimate relied upon.

However, when working in posterior teeth with complex root canals more information can be obtained from the working length radiograph than simple length confirmation. Curves in the canals are particularly important when using rotary instruments. The radiograph

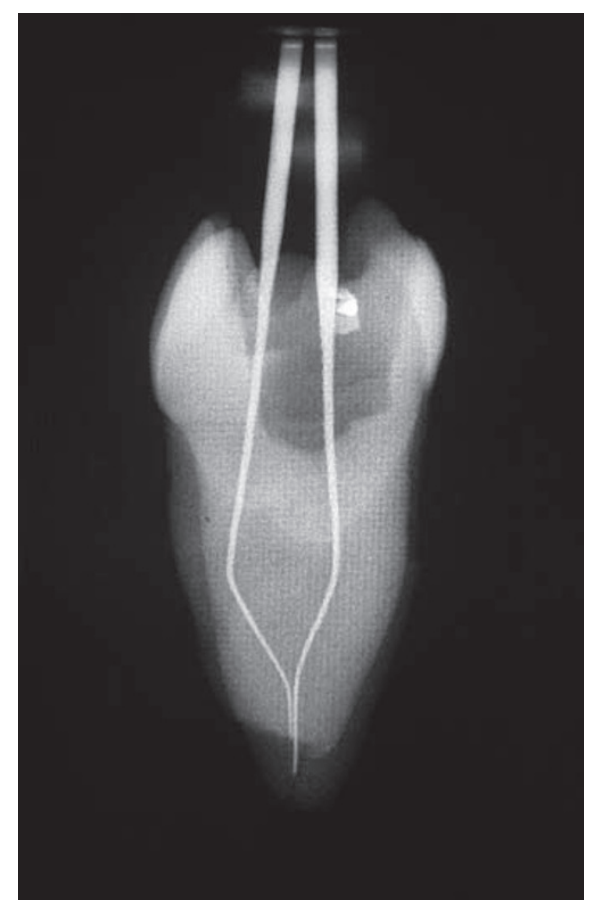

Fig. 5 A radiograph of an extracted tooth explored during a rotary instrumentation laboratory class. Note how the two canals in the mesial root unite in a common orifice

seen in Figure 4 shows a working length film of a tooth being treated following the separation of a NiTi instrument in one of the mesial canals. The double 'sshaped' curvature of the canal can be seen clearly. Had this shape been identified before treatment commenced the rotary instrument would have been kept well short of the second curve and the apical part of the canal prepared using hand-files, thus avoiding the file separation. Figure 5 shows a radiograph of an extracted tooth explored during a rotary instrumentation laboratory class. Note how the two canals in the mesial root unite in a common orifice.

\section{Obturation}

There have been two significant developments in canal obturation since $A$ clinical guide to endodontics was published: the introduction of synthetic filling materials and the further development of matching taper instruments and obturation devices.

Resilon $^{\mathrm{TM}}$ (Pentron Clinical Technologies, Wallingford, CT), a thermoplastic synthetic polymer-based root filling material, was introduced to endodontics in 2004. ${ }^{9}$ The authors claimed that in vitro research showed significantly less apical microleakage around this material 
compared to conventional obturation with gutta percha. The material, which contains bioactive glass and radiopaque fillers, has very similar handling properties to gutta percha, but incorporates adhesive technology. The shaped and cleaned root canal is first treated with a self-etch primer which improves the bond of the sealer to the dentine walls. In addition the sealer adheres to the Resi$\operatorname{lon}^{\mathrm{TM}}$ master cone resulting in what is termed a 'monobloc' of filling material.

Another recently introduced material is GuttaFlow by Roeko (Coltene Whaledent, West Sussex). In this material gutta percha particles are incorporated in a silicone based sealer which is compacted into the root canal by a single master gutta percha cone. A presentation at the European Society of Endodontology ${ }^{10}$ reported better sealing with this material than with the polymer-based system.

Many manufacturers now present root canal preparation and obturation systems with matching tapered instruments and gutta-percha points or heated carrier systems. Gulsahi et al. ${ }^{11}$ compared the amount of sealer remaining at different levels of the canal system when either cold lateral compaction of gutta percha points or one of two coated carrier systems was used. Their conclusion supported a significant improvement in the quality of the obturation with the carrier devices. Figure 6 shows the obturation carried out by a final year undergraduate dental student in the first case she had treated clinically using Protaper ${ }^{\circledR}$ (Dentsply, UK) files and matching Thermafil (Dentsply, UK) devices.

While the endodontic literature is replete with reports of in vitro research of microleakage tests by various means, what are lacking are randomised controlled clinical trials comparing the long-term clinical outcomes when cases are obturated using different systems. Practitioners have been reluctant to purchase these new and significantly more expensive materials without this clear clinical evidence. It is perhaps worth recalling the work by Klevant and Eggink, ${ }^{12}$ referred to in the original text of Endodontics in practice, who showed that when all the infection was removed from the root canal system obturation was not necessary to obtain healing.

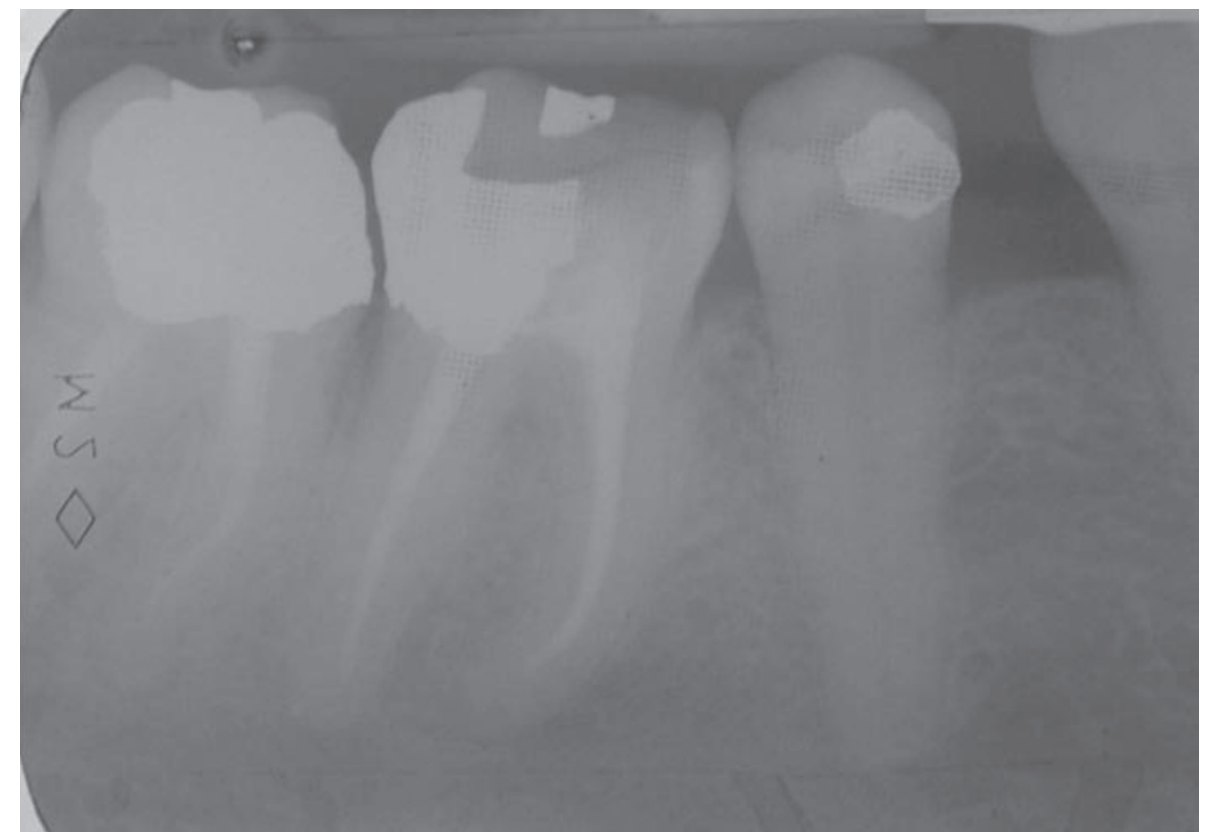

Fig. 6 A radiograph showing the obturation carried out by a final year student in the first case she had treated clinically using Protaper ${ }^{\circledR}$ (Dentsply, UK) files and matching Thermafil (Dentsply, UK) devices. The working lengths were confirmed using an apex locator

There can be no doubt that a good root canal filling will prevent re-infection of the root canal from the periradicular tissues leading to late failure and these microleakage tests are indeed valid. However, the aforementioned clinical trials are urgently needed to enable practitioners to make informed decisions.

\section{ENDODONTIC SURGERY}

The surgical principles and procedures described in part 11 of $A$ clinical guide to endodontics ${ }^{13}$ are largely unchanged. However, there is a sentence in the section entitled 'Retrograde cavity preparation' which reads 'The clinician practising without the aid of magnification must be aware of these difficulties, and the consequent reduction in prognosis of the surgery'. ${ }^{13}$ In the first edition of the textbook Essential endodontology, ${ }^{14}$ published in 1998, Shimon Friedman presented the prognosis of various endodontic procedures following an extensive review of the international endodontic literature. From 31 papers published between 1966 and 1997, the weighted average results for periradicular surgery were successful $66 \%$, uncertain $20 \%$ and failure 14\%. Since that publication many papers have been published showing that with the aid of an operating microscope, and also with the use of better retrograde filling materials including mineral trioxide aggregate (MTA), this prognosis may be significantly improved. In the second edition of Essential endodontology, published in 2008, ${ }^{15}$ Friedman details a further 17 such papers which show an average success rate of over $88 \%$.

Taschieri et al. ${ }^{16}$ reported 93\% success, 4\% uncertain and 3\% failure using microsurgical techniques. Tsesis et al. ${ }^{17}$ compared a significant increase in the results of a microsurgical approach versus conventional surgery, 91\% compared to $44 \%$. Microsurgery has been used in medical surgical procedures for some considerable time, so perhaps modern dentistry is just catching up with its medical colleagues. However, as observed at the start of this paper, clinicians wishing to carry out endodontic surgery to today's accepted standards are recommended to refer to the relevant specialist surgical texts and seek appropriate further training.

Reference may also be made here to the increasing use of mineral trioxide aggregate in all aspects of endodontic treatment, not just retrograde sealing in apicectomy procedures. The material and its applications were discussed in the textbook but MTA is now regarded as the material of choice in almost all surgical procedures such as apexification, 
resorptions and perforation repair. Furthermore, a number of papers have appeared on the subject of pulp capping with MTA, although this was originally described in $1996 .{ }^{18}$ The material, a soft white paste, is not difficult to use once the practitioner has mastered the correct mixing and placement techniques. It is anticipated that MTA will quickly become a routine part of everyday general practice.

\section{CONCLUSIONS}

Dental practice continues to develop in both practical techniques and scientific knowledge and understanding. The modern practitioner has a professional obligation to keep up to date. The changes can be so rapid that published textbooks quickly become out of date. This article has considered recent changes in preparation and obturation of the root canal system. The next paper will consider changes in paediatric endodontic practice, in particular the treatment of the primary dentition.
1. National Institute for Health and Clinical Excellence. Prophylaxis against infective endocarditis. London: National Institute for Health and Clinical Excellence, 2008. NICE clinical guideline 64

2. Buhrley L J, Barrows M J, BeGole E A. Effect of magnification on locating the MB2 canal in maxillary molars. J Endod 2003; 28: 324-327.

3. European Society of Endodontology. Quality guidelines for endodontic treatment: consensus report of the European Society of Endodontology. Int Endod J 2006; 39: 921-930.

4. Hsieh Y D, Gau C H, Kung Wu S F, Shen E C, Hsu $\mathrm{PW}$, Fu E. Dynamic recording of irrigating fluid distribution in root canals using thermal image analysis. Int Endod J 2007; 40: 11-17.

5. Radcliffe C E, Potouridou L, Qureshi R et al. Antimicrobial activity of varying concentrations of sodium hypochlorite on the endodontic microorganisms Actinomyces israelii, A. naeslundi, Candida albicans and Enterococcus faecalis. Int Endod J 2004; 37: 438-446.

6. Bonsor S, Nichol R, Reid T, Pearson G. An alternative regimen for root canal disinfection. Br Dent J 2006; 201: 101-105.

7. Witton R, Brennan P A. Severe tissue damage and neurological deficit following extravasation of sodium hypochlorite solution during routine endodontic treatment. Br Dent J 2005; 198: 749-750.

8. Molander A, Caplan D, Bergenholtz G, Reit C. Improved quality of root canal fillings provided by general dental practitioners educated in nickeltitanium rotary instrumentation. Int Endod J 2007; 40: 254-260

9. Shipper G, Orstavik D, Teixera F, Trope M. An evaluation of microleakage in roots filled with a thermoplastic synthetic polymer-based root canal filling material (Resilon). J Endod 2004; 30: 342-347
10. Taranu R, Wegerer U, Roggendorf M, Ebert J, Petschelt A, Frankenberger R. Leakage analysis of three modern root filling materials after 90 days of storage. Presented at the 12th Biennial Congress of the European Society of Endodontology, September 15-17 2005, Dublin, Ireland.

11. Gulsahi K, Cehreli Z, Kuraner T, Dagli F. Sealer area associated with cold lateral condensation of gutta-percha and warm coated carrier systems in canals prepared with various rotary NiTi systems. Int Endod J 2007; 40: 274-281.

12. Klevant F J, Eggink C O. The effect of canal preparation on periapical disease. Int Endod J 1983; 16: 68-75.

13. Carrotte P. Surgical endodontics. Br Dent J 2005; 198: 71-79.

14. Friedman S. Treatment outcome and prognosis of endodontic therapy. In Ørstavik D and Pitt Ford T R (eds) Essential endodontology. Chapter 15. Oxford: Blackwell Science, 1998.

15. Friedman S. Expected outcomes in the prevention and treatment of apical periodontitis. In Ørstavik $\mathrm{D}$ and Pitt Ford T R (eds) Essential endodontology. 2nd ed. Chapter 14. Oxford: Blackwell Munksgaard, 2007.

16. Taschieri S, Del Fabbro M, Testori T, Francetti $L$, Weinstein R. Endodontic surgery using two different magnification devices: preliminary results of a randomized controlled study. J Oral Maxillofac Surg 2006; 64: 235-242

17. Tsesis I, Rosen E, Schwartz-Arad D, Fuss Z. Retrospective evaluation of surgical endodontic treatment: traditional versus modern technique. J Endod 2006; 32: 412-416.

18. Pitt Ford T R, Torabinejad M, Abedi H R, Bakland L $\mathrm{K}$, Kariyawasam S P. Using mineral trioxide aggregate as a pulp-capping material. J Am Dent Assoc 1996; 127: 1491-1494. 